tional grammar and, in particular, the approach to language developed by the artificial intelligentsia working with computers. One suspects that they made a deliberate editorial decision to exclude this work-a great pity because many of the issues that they fail to resolve look more than susceptible to a procedural approach. In most other respects, however, the book is successful. Again and again, one is impressed by the authors' ability to think beyond an 'obvious' approach to a topic. They take a discerning route through the literature; and it is a real intellectual pleasure to follow in their footsteps.

The book is sophisticated but accessible. It is the definitive defence of the relevance of Chomsky's work to psycholinguistics, unlikely to be surpassed in its scope or thoroughness. Yet the defence fails. At the one point at which the general theory of transformational grammar is empirically vulnerable, it is all too vulnerable. The book probably marks the end of an era. It is unlikely that anyone will ever again mount so comprehensive a defence of transformational psycholinguistics. Monsieur Jourdain may go back to speaking simple prose.

\section{Slipper animalcule}

Paramecium : A Current Survey. Edited by W. J. Van Wagtendonk. Pp. xviii+ 499. (Elsevier Scientific: Amsterdam, London and New York, 1974.) \$53.90.

THE genus Paramecium is familiar to most biologists and to many other scientists because it occupies a place in most courses on elementary biology. The amount of attention that has been paid to it in biological research is reflected in the fact that it has been the subject of more than 4,000 scientific papers and 4 monographs, the most recent of which is this volume edited by Professor Van Wagtendonk.

The book contains eight chapters contributed by workers actively engaged in research using Paramecium, and is said to provide "an up-to-date evaluation of research on all aspects of Paramecium biology." The eight subjects covered are: morphology, taxonomy and general biology; mating types; surface antigens; behaviour and motor responses; growth patterns and morphogenesis; structure; nutrition; and intracellular particles. Most chap-

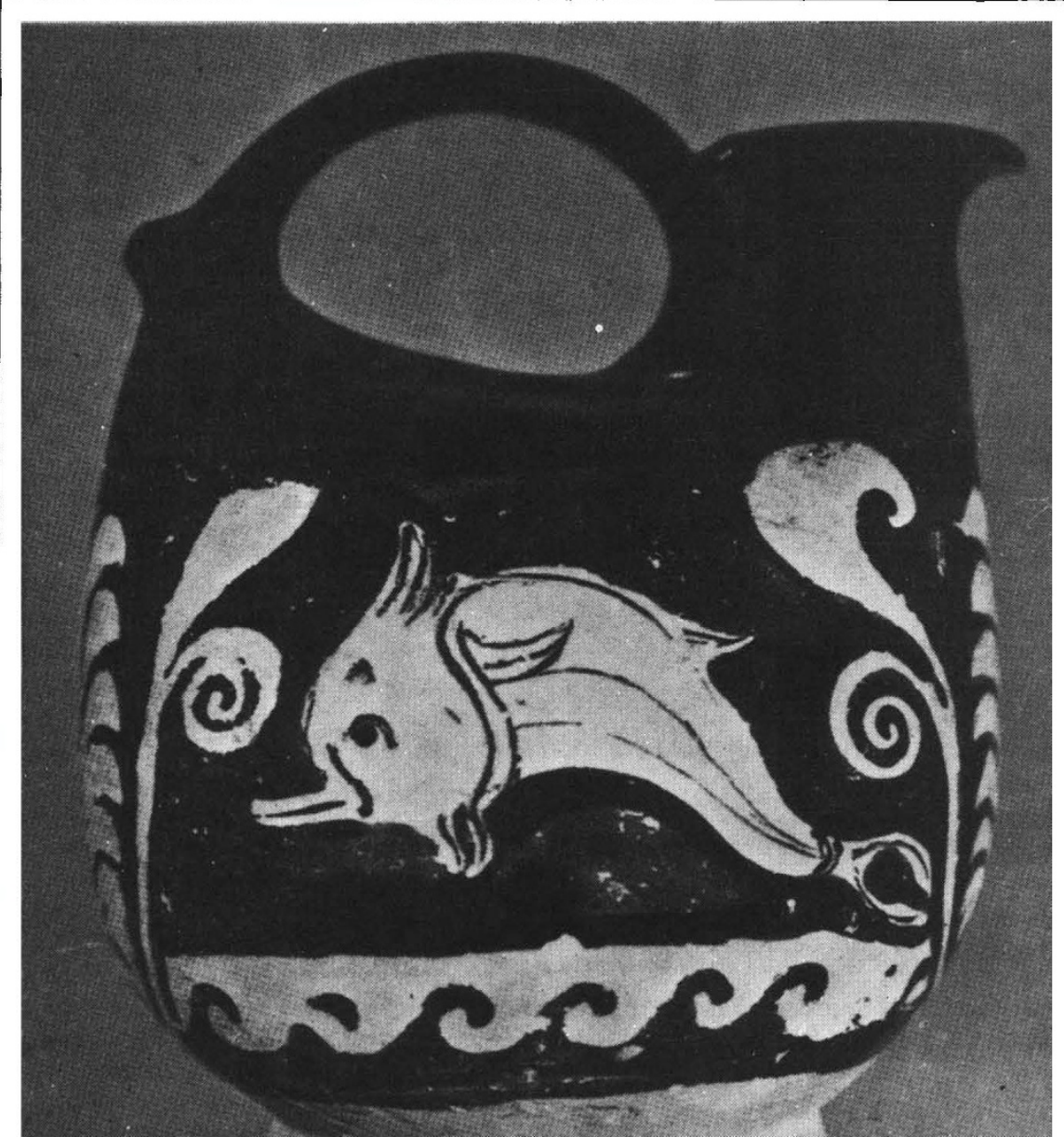

A Greek dolphin ceramic from the fourth century BC. From Dolphins (The Undersea Discoveries of Jacques-Yyes Cousteau). By Jacques-Yves Cousteau and Philippe Diolé. Translated by J. F. Bernard. Pp. $304+105$ colour photographs. (Cassell: London, May 22, 1975.) $£ 5.00$. ters refer to the literature published up until 1969 or early 1970 , though all are provided with addenda in which reference is made to work of the following two or three years. There is also a comprehensive bibliography of publications on Paramecium since 1953, the date of an earlier monograph on the subject by Wichterman.

The general introductory chapter by Vivier will be found the most useful by the average reader because it can be understood without much previous knowledge of the organism. This is not generally true of the other chapters, several of which assume an extensive background knowledge about the organism and specific facets of its bio$\operatorname{logy}$, to which one is not introduced elsewhere in this book; most readers will not find such chapters fully comprehensible without preliminary reading of earlier work. All of the authors have, however, given an interesting account of the new knowledge being discovered at the frontiers of research upon $\mathrm{Para}$ mecium and all of the chapters contain much useful information for the protozoologist and cell biologist engaged in research and teaching, which recommends this volume as a valuable work of reference.

The reader will not find here any extensive information on nuclear function, on general physiological activities such as ionic regulation, contractile vacuole function or respiration, or on a number of minor facets of research on Paramecium, so that the monograph is not a comprehensive work. In a chapter on nutrition one might expect to find an account of the types of food eaten and the manner of entry into the body; not just a very detailed survey of the chemical dietary requirements for the growth of the animal. The view that mating types correspond to sexual types (p. 68) is less satisfying than the view that every Paramecium is hermaphrodite, producing gametic nuclei of both sexes, with mating types acting as devices to encourage cross fertilisation, analogous to self sterility and similar mechanisms that ensure cross pollination in plants. In the magnificently illustrated chapter on structure, a conventional analytical approach would have more successfully presented the information than the attempted synthetic method by which the authors built up a view of the structure from the component molecules, macromolecules and organelles.

The book is illustrated with a large number of electron micrographs and many other figures of a uniformly high standard. Errors and omissions in the figures, legends and tables are few, but are irritating and probably could have been avoided, although there are commendably few spelling errors.

Michael A. Sleigh 